\title{
Sustainable utilization of polyethylene terephthalate in producing local precast flooring concrete slabs
}

\author{
Laith Mohammed Ridha Mahmmod ${ }^{1}$, Zainab M. R. Abdul Rasoul ${ }^{1}$, Mushtaq Sadiq Radhi ${ }^{1}$, Wajde S. S. Alyhya ${ }^{1}$ \\ ${ }^{1}$ University of Kerbala, College of Engineering, Civil Engineering Dept. Karbala, Iraq
}

\begin{abstract}
A polyethylene terephthalate plastic material is widely used in Iraq for packages manufacturing, especially for the mineral water bottles. They turn out to be waste very rapidly due to their particular short period of use. Furthermore, the recycling amount of polyethylene terephthalate bottles is considerably fewer than the sales of virgin polyethylene terephthalate manufacture for public consumptions. In the current research, the results of rupture load, water absorption and density tests implemented on precast flooring concrete slabs reinforced by fibers prepared from waste polyethylene terephthalate bottles are reported. The fibers were prepared by the simple cutting way to the bottles of carbonated beverage, and then the fibers are incorporated in the ordinary concrete mix in different volume fraction and aspect ratio. The outcomes of the rupture load and water absorption of the plastics fibers reinforced precast flooring concrete slabs exhibited apparent increase when compared with the plain precast flooring concrete slabs. This can offer the potential and practical use of the waste plastic in the development of the production of precast flooring concrete slabs.
\end{abstract}

Keywords: $\quad$ Concrete slabs, Sustainability, PET Fiber, Rupture load, Reinforcing

\section{Corresponding Author:}

Second Author,

Civil Engineering Departement,

University of Kerbala,

Email: zainabm@uokerbala.edu.iq

\section{Introduction}

The reasonable cost and adaptable performance of concrete make it as one of the best building materials for many applications. Concrete performs well under compression, but, it is likely to be brittle or weak in tension. Tensile stress, in addition to plastic shrinkage through the curing stage, leads to cracks, which make them susceptible to moisture access [1]. A great deal of the productions plants of local precast flooring concrete slabs is permanently suffering from the nonconformity of the quality control testing, and they do not satisfy the requirement of the Iraqi standard specification [2]. Gradually, innovative solutions to overtake the concrete limitations were evolved. Fibers are generally used as an additional material, which assists in augmenting the tensile and flexural strengths of concrete. Polymeric fibers, which utilized as concrete reinforcements are made from polyester, polypropylene, nylon, aramid, polyethylene, etc. Owing to easy handling and lightweight, polyethylene terephthalate (PET) bottles substituted glass bottles as a packing container. PET bottles manufacture and disposal has amplified dramatically over time [3]. Kandasamy and Murugesan [4] investigated the effect of adding waste polythene fibers from domestic waste at a percentage of $0.5 \%$ by mass of Portland cement on the mechanical properties of concrete. Some of the results obtained increasing in the compressive strength and tensile strength at 28 days by the rate of $3.8 \%$ and $1.6 \%$ respectively. Marthong [5] used different dimensions and geometries of PET fibers and studied their effects on the mechanical properties of concrete. The outcomes from this study exhibited a small effect of fibers geometries on the workability while improved the workability by smaller dimensions. Nivetha et al [6] used plastic waste (PET) with the conjunction of fly ash and quarry dust at varying fractions (25-35\% fly ash $25 \%$ and quarry dust $40-50 \%$ in weight) to make a paver block. The findings of physical and mechanical properties demonstrated that paver blocks contain plastic waste offered better properties than concrete paver blocks. Maqbool and Sood [7] carried out several trials to improve the behavior of PET fibers incorporated concrete, particularly the tensile and flexural strengths. The conclusions indicated that the mechanical properties have 
enhanced at definite PET fiber proportion and then tended to exhibit an apparent decrease. Furthermore, the optimum strength value was achieved on a fraction of 3\% of PET fibers. Pereira et al [8] used the PET bottles to optimize the compression and tension properties of concrete. The results exhibited a direct effect of fiber length on the performance of concrete principally tensile. Another local study was conducted by Ref. Abdul Rasool et al [9] by using wire mesh reinforcement with different shapes and types (metal and plastic wire mesh) to improve the properties of precast concrete. The outcome of the study exhibited that the properties of the precast concrete can be developed by using reinforcing mesh.

In the present study, the effect of polyethylene terephthalate bottles waste (PET) that used as fiber on the behavior of local precast flooring concrete slabs was examined. Thus, the use of this fiber to improve rupture load, absorption, and density of flags.

\section{Experimental works}

\subsection{Materials}

Materials used for producing local precast flooring concrete slabs were cement, coarse aggregate, and fine aggregate, and polyethylene terephthalate (PET) waste fibers. Sulfate-resisting Portland cement (Al-Gesr type manufactured in Karbala cement factory) locally available was used for the concrete mixes. Al-Ekhaider naturally acquiring sand was utilized as fine aggregate with a maximum size of $4.75 \mathrm{~mm}$. The dry density equals to $1720 \mathrm{~kg} / \mathrm{m}^{3}$, and the modulus of fineness of 2.97. Al-nba' ay crushed gravel of $10 \mathrm{~mm}$ maximum size was utilized as coarse aggregate to produce concrete mixes. The sieve analysis testing results specify that the grading of the fine and coarse aggregate conforms to Iraqi standard specification limits [10]. Fig. 1 illustrates the grading curve for coarse and fine aggregates used through this study and the limits of Iraqi standard specification limits [10]. PET waste fibers used were prepared via simple cutting manner to the bottles of carbonated beverage. The bottom and the neck of the plastics bottles were omitted, and the remaining body to each bottle was torn to fibers, to acquire similar fibers of constant thickness. The plastic bottles were torn to two lengths of $3 \mathrm{~mm}$, and $1.5 \mathrm{~mm}$ with $1.5 \mathrm{~mm}$ width to each. Figure 2 displays the two-tore PET waste fibers. The dry density of PET waste fibers was around $350 \mathrm{~kg} / \mathrm{m}^{3}$.
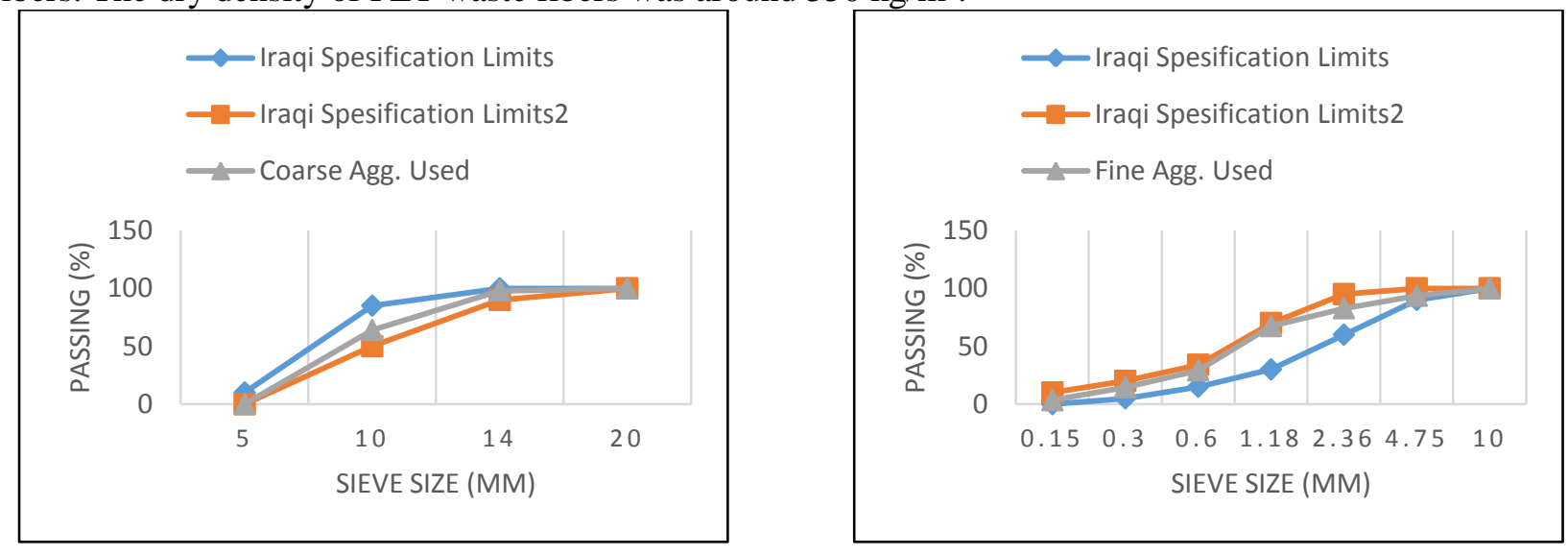

Figure 1. Grading curves for coarse and fine aggregates

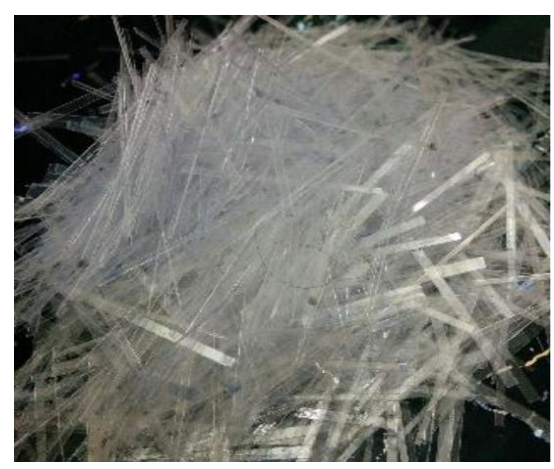

Figure 2. PET Fiber 


\subsection{Proportions of concrete mix and mixing}

In the present study, tests were performed on concrete with normal compressive strength equal to $25 \mathrm{MPa}$. The mix design of the concrete was prepared on weighting basis according to the British mix design method. The proportion of the concrete mix was 1:1.9:2.75 (cement: sand: gravel) and w/c was 0.5 . The percentage of the PET fibers incorporated to the concrete mixture commonly from $1.5 \%$ to $3.0 \%$.

The adopted manner to manufacture the PET fibers reinforced concrete is itemized as follows. Initially, the coarse aggregate and fine aggregate were delivered into a tilting concrete mixer, and then dry mixed for one minute. Subsequent, the Sulfate-resisting Portland cement was supplied and distributed into the mixer and dry mixed for one minute too. At that time, The PET fibers were manually spread and mixed for three minutes in the mixture, in accordance with above-identified percentages. Water was then delivered with an additional five minutes mixing interval. Slump test was executed before the moulding process of the specimens. High workability is not significant for precast concrete slabs; so adopted consistency of fresh concrete by cone slump test was ranged between 50 to $75 \mathrm{~mm}$.

\subsection{Casting of the specimens and curing}

Local precast flooring concrete slabs were made in MDF wooden moulds. Dimensions of the moulds were designed to specify the requirement of Iraqi standards specification. Specimen moulds of size $400 \mathrm{~mm} \times 200$ $\mathrm{mm} \times 50 \mathrm{~mm}$. The concrete mix was poured in the prepared moulds after lubricating the inner surfaces of the moulds with thin oil coats for easy demolding. An electric vibrating table was utilised to compact the concrete mix inside the mould. Blocks and slabs were manufactured with two layers by the vibration on the table for one minute. Follow the compacting process, the excess concrete was eliminated, and the top surface was smoothed using a stainless-steel trowel. Then, the specimens were kept in moisture condition for 24 hours. Next day, specimens were de-moulded and cured into tap water for 27 days.

\subsection{Specimens perpetration and testing}

After 28 days of curing in a water bath, the precast flooring concrete slabs were dried in the laboratory temperature for an hour. Then, the flexural test for these slabs was conducted according to the Iraqi Specification [2], as shown in Figure 3. Control specimens $(100 \mathrm{~mm} \times 100 \mathrm{~mm})$ cubes were tested to determine the compressive strength conferring to the British Standards method of [11], and $(100 \mathrm{~mm} \times 200$ $\mathrm{mm}$ ) cylinder specimens to compute the splitting tensile strength according to the ASTM C-496 [12].

\section{Discussion of the results}

\subsection{Rupture load}

Figure 4 presents the rupture load development of the specimens unreinforced and reinforced with (PET) with different volume fractions. All values are the average of three test results. The specimens were cured for 28 days at $\left(23 \pm 2^{\circ} \mathrm{C}\right)$ and $(100 \%) \mathrm{RH}$. For all types of the precast flooring concrete slabs, the specimens were tested at ages of 14 and 28 days to observe the development of rupture load for all specimens.

Over the whole range of curing period (14 - 28 days) the differences between the rupture load of reinforced and unreinforced specimens are clearly evident. However, the results clearly demonstrate that the rupture load of reinforced flags specimens are always higher than those exhibited by the unreinforced flags specimens at the same testing age, especially for the fiber volume fraction of $(1.5 \%)$ with length of $(3 \mathrm{~cm})$. On the other hand, the calculated percentage of rupture load increasing by about (39\%) and (46\%) at (14) and (28) days, respectively. It is noteworthy that the reinforced flags specimens exhibited a significant reduction of crack extension due to loading, substantial similarity is that PET fibers do not harm rupture load with longer curing age (28 days), adversely a higher rupture load was obtained at this period of curing.

Figure 5 (a) and (b) shows the influence of length and volume fraction of PET fibers on the (14) days and (28) days rupture load of the specimens reinforced with it. In these figures, the variations of rupture load with the different volume fraction of PET fibre are also reported. These figures manifested that the rupture loads are significantly higher for reinforced flags specimens with longer PET fibers with same volume fraction, reflecting the increased reinforcing effectiveness attributable to more fabulous fibers length with consequently higher aspect ratio.

The breaking process of fibre-reinforced flags consists of slowly de-bonding of fibers from the matrix, during slow crack extension occurs, final breaking happens when fibers completely pullout with unstable cracks extension appear over the specimen. The reinforcing effectiveness of PET fibers in improving rupture load of 
reinforced specimens comparison with unreinforced specimens, could be described as, when matrix cracks, PET fibers will support the load that supported by concrete until de-bonding of it from the matrix and cracking by interfacial bond between matrix and fibres. On the other hand, PET fibers delay the growth of cracks, enhance the brittle nature and increase the toughness of concrete by transmitting stresses across the cracked section. This behaviour of fibre-reinforced concrete has been reported and established earlier [13-14]. Several previous researchers have used PET fibers to sustain properties of concrete. The scope of the present research is certainly usfel in utilizing PET fibers improve the properties of a local product frequently that does not match the requirements of Iraqi standard specification limits [2], especially rupture load limits.

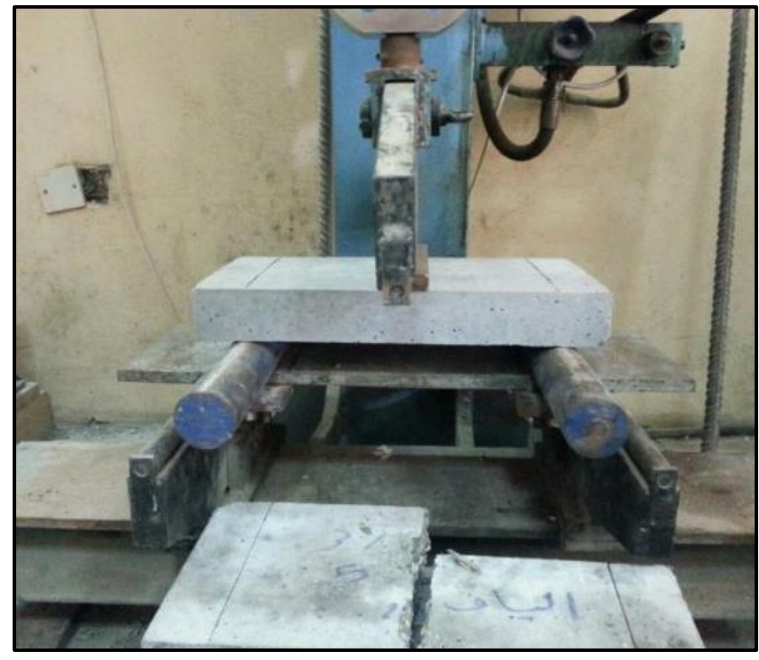

Figure 3. Flexural test of slab

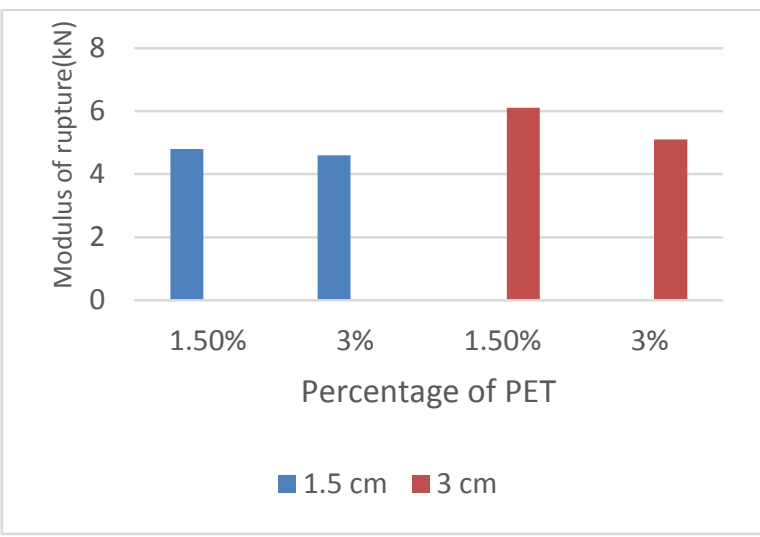

(a)

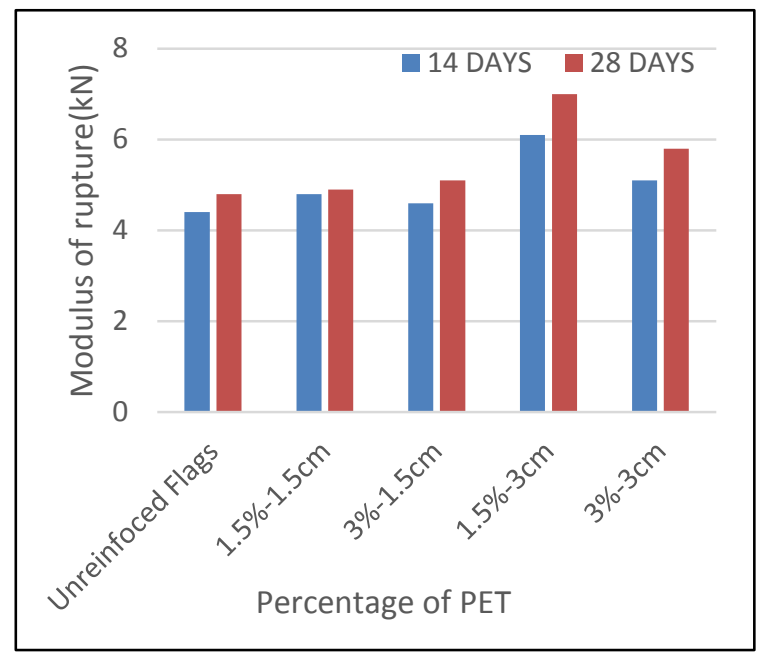

Figure 4. Rupture load of reinforced concrete slabs comparison with unreinforced concrete slabs

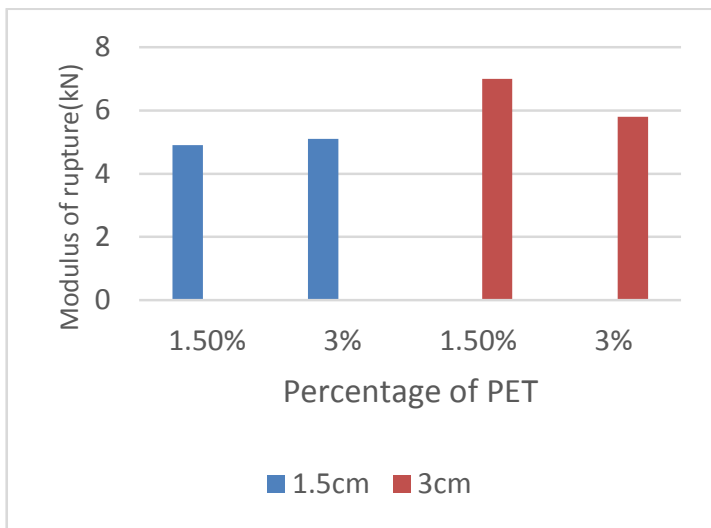

(b)

Figure 5. Effect of length and percentage of PET on the rupture load at the age of (a) 14 days and (b) 28 days

\subsection{Absorption}

The second requirements of the Iraqi standard specification limits [2] are water absorption of slabs specimens. An important indicator of the pore structure and hence the concrete durability performance, which has been widely acknowledged by researchers, engineers and codes of practice. The importance of minimising absorption ability of concrete flags helps in achieving a high degree of durability during service and make it able to withstanding the environments, as concrete slabs used for roofing purpose, which greatly influenced by aggressive conditions. Water absorption of all specimens is calculated after watery cured of 28 days with conducted to the Iraqi standard specification limits [2]. This test is accomplished by immersion specimens with water at atmospheric pressure for 24 hours. After that, they wiped, and the saturated surface dry weights were reported, based on differential weight. The percentages of absorption were calculated, and the mean results of three specimens are portrayed as shown in Figure 6 . The average of three specimens at age 28 days for each mix was used to calculate their water absorption. From Figure 6, it can be noted a decrease in the absorption ratio with respected to reference specimen as the ratios of decrease were $51 \%, 47 \%, 32 \%$, and $60 \%$ 
for percentage PET $1.5 \% 1.5 \mathrm{~cm}, 3 \% 1.5 \mathrm{~cm}, 1.5 \% 3 \mathrm{~cm}$, and $3 \% 3 \mathrm{~cm}$ respectively. These decrements could be attributed to the ability of PET fibre in reducing the formation of cracks and control its distribution resulting in minimising the ability of concrete to absorb water.

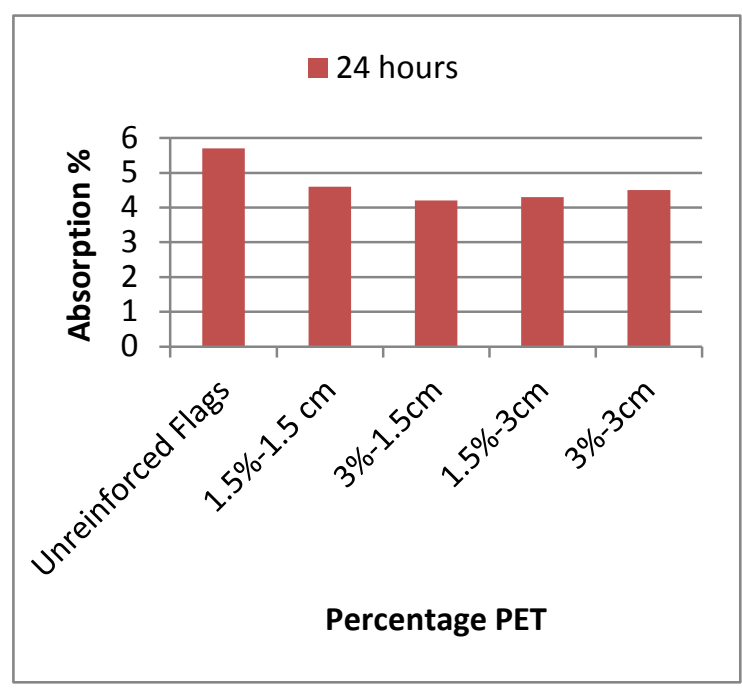

Figure 6. Absorption of reinforced concrete slabs comparison with unreinforced concrete slabs

\subsection{Density}

At age 28 days, the average of three specimens for each mix was used for the density test. Figure 7 gives details regarding the influence of the adding percentage of PET fibers on the density of concrete precast slabs. From that figure, it can be observed a decrease in the density of the precast slabs for all percentage of PET. The percentages of reduction compared to the reference specimen were $(-1 \%,-2 \%,-1 \%$, and $-1 \%)$ for percentage PET $1.5 \% 1.5 \mathrm{~cm}, 3 \% 1.5 \mathrm{~cm}, 1.5 \% 3 \mathrm{~cm}$, and $3 \% 3 \mathrm{~cm}$ respectively. This reduction is due to the lightweight of PET and its homogenous distribution in the precast slabs.

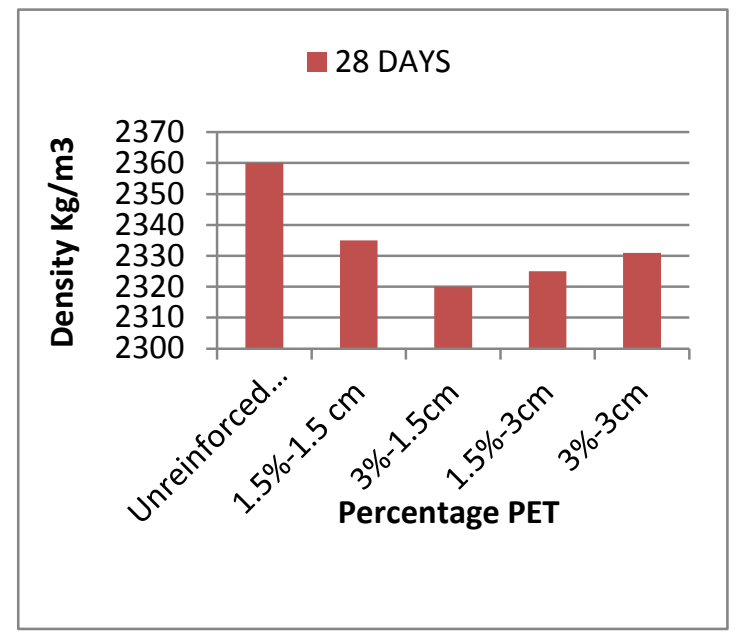

Figure 7. Density of reinforced concrete slabs comparison with unreinforced concrete slabs

\section{Conclusions}

Referring to the results of this study, the following conclusions can be drawn:

- It can be concluded that the addition of PET fibers to normal concrete mix can increase the rupture loads. The percentages of increase were 5\%,9\%,39\%, and $16 \%$ at age 14 days and $0 \%, 6 \%, 46 \%$, and $21 \%$ at age 28 days for percentage PET $1.5 \% 1.5 \mathrm{~cm}, 3 \% 1.5 \mathrm{~cm}, 1.5 \% 3 \mathrm{~cm}$, and $3 \% 3 \mathrm{~cm}$ respectively. The mixes 
that contain fibre of $3 \mathrm{~cm}$ length exhibited more improvement in rupture load compared with mixes contained fibre have $1.5 \mathrm{~cm}$ length.

- All mixes with different percentage of PET gave the results of absorption ratio less than the control mix (mix without fibre).

- The decrease in density of concrete precast slabs occurred when adding a different percentage of PET. The ratio of reduction in density at age 28 days ranged about (-1\%) to $(-2 \%)$.

\section{References}

[1] S. Black, "Composites and Concrete." Technical editor c1107 composites technology, Internet, http:www.compostesworld.com, pp.11 April 2005.

[2] Iraqi Specification No. "Precast Concrete Flags". Central Organization for standardization and quality control, Ministry of Planning, 1988.

[3] C. Marthonga and S.K. Sarma, "Influence of PET Fibre Geometry on the Mechanical Properties of Concrete: an Experimental Investigation", European Journal of Environmental and Civil Engineering, pp.1-14, October 2015.

[4] R. Kandasamy and R. Murugesan, "Fibre-Reinforced Concrete Using Domestic Waste Plastics as Fibres", ARPN Journal of Engineering and Applied Sciences, Vol. 6, No. 3, March, pp.75-82, 2011, ISSN 1819-6608, www.arpnjournals.com.

[5] C. Marthong, "Effects of PET Fibre Arrangement and Dimensions on Mechanical Properties of Concrete", The IES Journal Part A: Civil \& Structural Engineering, Vol. 8, No. 2, pp.111-120, 2015.

[6] C. Nivetha, M. Rubiya, S. Shobana, R.G. Vaijayanthi, M.E.Viswanathan and R.M.E.Vasanthi M.," Production of Plastic Paver Block from The Solid Waste (Quarry Dust, fly ash \& PET)", ARPN Journal of Engineering and Applied Sciences, Vol.11, No.2, January, pp.1078-1079, 2016, ISSN 1819-6608, www.arpnjournals.com.

[7] S. Maqbool and H. Sood," Effect of PET Fibres on the Mechanical Properties of Concrete", SSRG International Journal of Civil Engineering (SSRG-IJCE), Vol. 3 Issue 12 , pp.1-6, December, 2016.

[8] E.L Pereira, A.L.O Junior, and A.G. Fineza, "Optimization of Mechanical Properties in Concrete Reinforced with Fibres from Solid Urban Wastes (PET Bottles) for the Production of Ecological Concrete", Construction and Building Materials, 149, pp.837-848, May, 2017, journal homepage: www.elsevier.com/locate/conbuildmat.

[9] Z. M. R. Abdul Rasool, , L.M.R .Mahmmod, and M.S Radhi, "Effect of the Wire Mesh Reinforcement on some Properties of the Precast Concrete Flags", Al-Qadisiyah journal for engineering and science, Vol. 11, No. 2,pp.256-269, 2018.

[10] Iraqi Specification No 45, "Aggregate from Natural Sources for Concrete and Construction " Central Organization for standardization and quality control, Ministry of Planning, 1984.

[11] British Standards Institution. B.S 1881, Part 116, "Method for Determination of Compressive Strength of Concrete Cubes", 1983.

[12] ASTM C 496, "Splitting Tensile Strength of Cylindrical Concrete Specimens", Annual Book of ASTM Standard 2015.

[13] A.M. Neville, and J.J. Brooks, "Concrete Technology", 2nd Edition, London: Longman Group, 2010.

[14] M.S. Shetty, " Concrete Technology: Theory and Practice", First Multicolour edition, India, S. Chand and company LTD, 2005. 